\title{
AUTONOMÍA Y ADAPTACIÓN ORGANIZATIVA: LOS CENTROS DE INVESTIGACIÓN ANTE LOS CAMBIOS DEL ENTORNO
}

\author{
Luis Sanz Menéndez* \\ Consejo Superior de Investigaciones Científicas (CSIC) \\ E-mail: 1sanz@iesam.csic.es \\ Laura Cruz Castro* \\ Consejo Superior de Investigaciones Científicas (CSIC) \\ E-mail: laura.cruz@iesam.csic.es
}

\begin{abstract}
RESUMEN
El sistema de investigación es altamente dependiente de los recursos que le suministra el sistema político. Los investigadores tienen la expectativa de que el gasto público en $\mathrm{I}+\mathrm{D}$ aumente, pero el encarecimiento de la investigación y la emergencia de problemas financieros de los gobiernos han hecho perder relevancia en la agenda política a la ejecución directa de la I+D. Esa situación se ha observado en los centros de investigación de titularidad estatal en España, que han disminuido su peso en el conjunto de la actividad investigadora, mientras aumentaban los mecanismos de financiación competitiva como método de intervención gubernamental.

La reducción de las ayudas directas es un problema que afecta a las condiciones de ejecución de la investigación, tanto para los investigadores como para los centros. El objetivo de este artículo es analizar cómo un conjunto de centros de investigación públicos han respondido a la reducción de recursos transferidos directamente por la Administración. Tras constatar la diversidad de respuestas para adaptarse y hacer frente al descenso de las transferencias directas del Estado, se construye una explicación de carácter institucionalista basada en el nivel y el tipo de autonomía de que disponen los centros y los investigadores.
\end{abstract}

* Unidad de Políticas Comparadas, Grupo de Investigación sobre Políticas de Innovación, Tecnología, Formación y Educación (SPRITTE), C/ Alfonso XII, núm. 18 (E-28014 Madrid). Laura Cruz es también profesora asociada en el Departamento de Sociología de la Universidad Carlos III de Madrid. Se agradece la financiación recibida para esta investigación por la Unión Europea (Programa Marco de I+D), la Comisión Interministerial de Ciencia y Tecnología (CICYT) y la Comunidad de Madrid. También hay que mencionar la contribución a trabajos previos, ya publicados, de Sonia Alonso y José R. Fernández. 


\section{INTRODUCCIÓN}

Con la detonación de las bombas atómicas de Hiroshima y Nagasaki, la polémica sobre si el conocimiento científico tenía un impacto directo en el mundo moderno quedó definitivamente resuelta. Desde entonces el número de investigadores ha crecido de forma extraordinaria: en algunos países más del 1 por 100 de los ocupados se dedican a investigación y, en España, más de cien mil personas trabajan en $\mathrm{I}+\mathrm{D}$.

La teoría económica ha asignado al "cambio técnico» un papel central en la explicación del «crecimiento económico» (Solow, 1957; Romer, 1990). Posteriormente, el potencial investigador de los países se asoció con la competitividad de sus industrias en los mercados mundiales. Últimamente los organismos internacionales, como la OCDE o el Banco Mundial, han señalado la importancia de disponer de la capacidad de producir conocimiento que permita hacer sostenible el crecimiento económico de los países (OECD, 1996; Banco Mundial, 1999).

Hace más de cincuenta años que los gobiernos desarrollan políticas de investigación, se ha consolidado un "dominio político» (Burstein, 1991) y las políticas de I+D han cambiado y evolucionado (Averch, 1985; Elzinga y Jamison, 1995; Ruivo, 1994; Sanz Menéndez, 1997). En sus primeras intervenciones los gobiernos promovían la investigación por medio de la creación de centros públicos. A finales de los sesenta y en los setenta se establecieron mecanismos e incentivos para que universidades y empresas desarrollasen más investigación, primero por medio de los Consejos de Investigación (Research Councils) y luego a través de los programas de I+D estratégica (Rip, 1990). Hoy coexisten diversas formas de intervención de los gobiernos, cuya combinación varía según los países, pero las políticas de este campo consisten, generalmente, en mecanismos de asignación de recursos económicos y de definición de normas e incentivos.

El mundo de la investigación se ha transformado radicalmente; antes apenas existían más actores que los centros públicos de investigación y las universidades; hoy se han multiplicado los productores de conocimiento, así como los tipos de conocimiento producido (Gibbons et al., 1994), y los centros públicos de investigación coexisten, en un entorno cada vez más diverso y complejo, con universidades, empresas, centros tecnológicos, etc.

La investigación, especialmente en los centros públicos de $\mathrm{I}+\mathrm{D}$, es una actividad muy dependiente de los recursos externos (Solingen, 1993) en un contexto en el que se ha producido un salto cuantitativo en sus costes. Así pues, la investigación es muy sensible a los cambios de coyuntura, a las crisis políticas e incluso a las recesiones económicas que afectan a la disponibilidad de recursos para financiarla, tanto directa como indirectamente.

Hasta mediados de los setenta, los únicos lugares de desarrollo de la investigación en España eran centros (CSIC, INTA, JEN, etc.) dependientes de los Ministerios. En los años ochenta, en el contexto de las reformas promovidas 
por el gobierno del PSOE, el sistema se expandió de forma significativa; no obstante, los viejos actores de la investigación perdieron peso en términos relativos. Por otro lado, a lo largo de los años noventa, como consecuencia de la recesión económica, se observó un estancamiento e incluso una disminución, en términos constantes, de las transferencias directas de la Administración General del Estado a los centros de investigación que dependían de los diferentes Ministerios.

Para el desarrollo de la investigación en los centros públicos, la reducción de las transferencias directas se convirtió en un problema que amenazaba su propia actividad. Este artículo estudia las respuestas que los centros de investigación dieron a esos cambios en el entorno: ¿qué estrategias siguieron los centros para hacer frente a la reducción de la financiación directa por parte del Estado? Por otro lado, dado que la característica fundamental de la respuesta de los centros fue su diversidad, ¿cómo podemos explicar esa variación cuando se hicieron frente a problemas de financiación similares? ${ }^{1}$

Aunque no hay una teoría específica de cómo responden las organizaciones a los problemas (Schimank y Stucke, 1994a), la teoría de la organización y la sociología política nos ofrecen un marco analítico para situar nuestro trabajo, construido sobre la "dependencia de los recursos» y las respuestas "adaptativas»; a ello se dedica la sección segunda. En la sección tercera se describen los cambios en el sistema español de investigación, entorno esencial de los centros, así como aquellos centros seleccionados para el análisis. En la sección cuarta, ante los cambios en los niveles de financiación de la investigación, se observan las respuestas de los centros de investigación, que medimos por el grado y tipo de obtención de recursos externos no directamente presupuestarios. Dada la significativa variación en la respuesta por parte de las organizaciones, se construye una explicación basada en el grado de autonomía de los actores, tanto individuales como organizativos, y se especifican las dimensiones que componen esta variable.

${ }^{1}$ En este trabajo no se analizarán los cambios en el sistema de $\mathrm{I}+\mathrm{D}$ derivados del crecimiento de las organizaciones de investigación, sino cómo las organizaciones más antiguas, los centros públicos de investigación, han hecho frente a la transformación de su entorno y se han adaptado. En todo el mundo, los centros que ejecutan investigación, con dependencia directa de los gobiernos, han sufrido suertes muy diversas. Por ejemplo, en el Reino Unido se han privatizado centros de investigación durante los años del gobierno conservador de Margaret Thacher (Boden, Cox, Georghiou y Barker, 2001), en Estados Unidos se han reorientado las misiones de los Laboratorios Nacionales tras el final de la guerra fría (Jordan, 2001) y en los antiguos países del Este de Europa se ha observado bien el colapso total del sistema (Gonchar, 2001) o su integración en el Oeste (Mayntz, 1993). En definitiva, la suerte de estos centros públicos de investigación en los diferentes países ha sido distinta, dependiendo del tipo de relación establecida entre ciencia y política. 


\section{LA TEORÍA DE LA DEPENDENCIA DE LOS RECURSOS, LA TEORÍA INSTITUCIONAL Y LA EXPLICACIÓN DE CÓMO SE AFRONTAN LOS PROBLEMAS}

Dado que la suerte de los centros públicos de investigación es muy dependiente de la política, una perspectiva fructífera, desde el punto de vista analítico, es aquella que entiende las organizaciones como sistemas abiertos, que se mantienen sobre la base de un intercambio de recursos con su entorno. Dentro de esta perspectiva, la teoría de la dependencia de los recursos (Pfeffer y Salancik, 1978; Scott, 1981/1998; Thompson, 1967) parte de la premisa de que ninguna organización es autosuficiente, y mantiene que la necesidad de adquirir recursos para el desarrollo de sus actividades crea dependencia entre las organizaciones y algunos actores externos a las mismas. La naturaleza y el grado de esta dependencia vendrán determinados por la importancia de los recursos para lo que constituya el núcleo de la actividad del centro, y por la abundancia relativa de los mismos ${ }^{2}$. La dependencia caracteriza las sociedades complejas y, sin duda, al sistema de investigación, donde los investigadores dependen de los conocimientos producidos por otros investigadores para avanzar (De Solla Price, 1963) y de la financiación facilitada por el sistema político (Price, 1965).

La teoría de la dependencia de los recursos incorpora la idea de que las organizaciones pueden ser activas con respecto a su suerte. Por tanto, este enfoque es especialmente útil para dar cuenta de la adaptación y del cambio organizativo a corto plazo. Sin duda, la distinción entre el núcleo de la actividad organizativa y los elementos más periféricos es aquí relevante. Es improbable que las organizaciones sean capaces de emprender cambios estructurales con la misma rapidez con la que se producen cambios ambientales. Lo común es que, en caso de darse, los cambios afecten a las estructuras periféricas, es decir, a los elementos de conexión de la organización con aquellos de los que obtienen recursos y aquellos que utilizan sus resultados. Los miembros de las organizaciones, y de modo especial pero no exclusivo sus directivos, se relacionan activamente con el entorno, identificando problemas, oportunidades y amenazas, y buscando intercambios favorables. Todas las organizaciones dependen de los proveedores de inputs y de los usuarios de los resultados, y la selección concreta de los mismos es, en parte, una prerrogativa organizativa que permite reducir la dependencia de un solo proveedor o usuario. Las organizaciones y sus miembros serían, por tanto, capaces de cambiar y responder al entorno, de "gestionarlo». El propio concepto de «estrategia organizativa» no podría entenderse sin conferir a las organizaciones cierta capacidad de respuesta activa.

2 La dependencia es el reverso del poder, y el poder de un actor sobre otro es inversamente proporcional a la capacidad de éste de obtener recursos fuera de la relación con el primero (Emerson, 1962). 
El coste y la escala que ha adquirido la investigación científica hacen que la financiación pública se convierta en condición necesaria de la propia existencia del sistema de I+D. Además, los gobiernos, en lugar de ejecutar directamente la investigación, la delegan ${ }^{3}$ en diversos grados en otras organizaciones o actores que, en su defecto, carecerían de recursos para la misma; pero, en las últimas décadas, esta delegación ha tenido lugar en un contexto en el que los costes de la investigación se han multiplicado a la vez que los recursos públicos disponibles para la misma han disminuido en términos reales. Ante una situación de escasez relativa de los recursos, la teoría de la organización ayuda a describir la conducta de las organizaciones como respuesta adaptativa a ese cambio en el entorno ${ }^{4}$.

Al mismo tiempo que este trabajo adopta la teoría de la dependencia de los recursos, argumentamos, sin embargo, que las bases de la dependencia (o de su reverso, la autonomía) tienen un carácter institucional para cuya comprensión es imprescindible prestar atención a las bases sociales y normativas de la estabilidad y el cambio en las organizaciones (Meyer y Rowan, 1977; DiMaggio y Powell, 1983; Scott, 1995). Dado que los centros de investigación, como todas las organizaciones, se mueven simultáneamente en una diversidad de entornos, la teoría de la dependencia de los recursos es útil para entender las respuestas a cambios en el entorno de la financiación, pero también es importante prestar atención al entorno institucional y social ${ }^{5}$.

Si conceptualizamos el descenso de la financiación pública de la investigación como un problema derivado de un cambio en el entorno político-económico, las respuestas adaptativas de los centros de investigación pueden ser diversas. El análisis de los mecanismos a través de los cuales los investigadores y sus organizaciones afrontan los problemas se hace, en este trabajo, desde una perspectiva institucionalista, una perspectiva que, no obstante, tiene en cuenta a los actores y el modo en que éstos seleccionan una estrategia (conducta) de entre las posibles, en función de sus intereses, sus recursos, estructuras de oportunidad, etc. En este sentido, hay ciertos factores de carácter institucional relacionados con los incentivos que las normas organizativas implican, con el margen de maniobra que las estructuras de autoridad organizativa permiten y con las posibilidades de establecer vínculos con otros actores del sistema que, en conjunto, configuran el grado de autonomía o dependencia relativa de las organizaciones y de sus investigadores y a partir del cual es posible prever unas conductas frente a otras.

3 El problema de la delegación se ha analizado recientemente desde la perspectiva de las relaciones entre el principal y los agentes (Braun, 1993; Guston, 1996, y Van der Meulen, 1997).

${ }^{4}$ Existe en cierto modo una contradicción interna entre un sistema de acción, el de la ciencia, caracterizado por la autonomía cognitiva, y la fuerte dependencia del sistema de investigación de los recursos externos. Esta contradicción ha dado pie a diversas polémicas sobre las relaciones entre la ciencia y la política (véanse las aproximaciones clásicas en Bernal, 1939; Polanyi, 1963, o Price, 1965).

5 Este último entendido como el que proporciona los valores y las expectativas con respecto a los cuales las organizaciones deben comportarse. 
Se puede asumir que el objetivo principal de los actores implicados en la investigación es asegurar la continuidad de sus actividades: reproducirse. Por tanto, frente al problema que supone la disminución de fondos públicos disponibles, los investigadores y los centros de investigación pueden adoptar conductas diversas. De las posibles respuestas (Schimank y Stucke, 1994b), algunas de ellas son relativamente pasivas, en concreto aceptar la situación y no iniciar ningún tipo de acción que intente modificar los efectos del cambio en el entorno, mientras que otras son activas en diverso grado y van desde la prevención de los efectos de esos cambios, para lo cual los actores tienen que contar con la información antes de que se produzcan, hasta la adaptación activa. Esta última respuesta puede tomar dos formas, individual o colectiva. Ante el problema inducido políticamente que estamos tomando como referente, el de la disminución de la financiación directa, las organizaciones colectivamente, a través de sus directores, o los investigadores de modo individual podrían emprender acciones orientadas a la búsqueda de fuentes externas de financiación que permitiesen garantizar la continuidad de la actividad. Así se debería combinar el análisis en dos niveles de acción distintos, el del investigador individual y el del centro de investigación.

Por otro lado, se podría esperar que los centros públicos de investigación enfrentados a un problema común actuasen de forma similar para mantener sus condiciones de investigación. Las organizaciones de una misma población o de un mismo campo organizativo tienden a ser isomorfas (DiMaggio y Powell, 1983), especialmente si las normas reguladoras son las mismas. Por otro lado, este tipo de normas no agotan el contexto institucional en el que se mueven los centros de investigación y sus investigadores. Los incentivos individuales y colectivos a favor de cierto tipo de conductas, las estructuras de autoridad en las organizaciones, así como las condiciones de posibilidad que generan la existencia de mercados, usuarios y demandantes de investigación para ciertas áreas, son elementos institucionales que pueden llevar a la divergencia y no hacia la convergencia a organizaciones del mismo campo, y que pueden integrarse conceptualmente como niveles de «autonomía» de los actores en la ejecución de la investigación.

\section{LOS CENTROS DE I+D EN SU ENTORNO}

La ciencia y la tecnología habían languidecido en España durante el franquismo; sin embargo, el primer gobierno socialista, en 1982, formuló un compromiso de apoyo. A lo largo de los ochenta se produjeron incrementos significativos de financiación pública, que contribuyeron a que el nivel de gasto en I+D sobre el PIB pasase de un 0,55 por 100 en 1982 a casi el 1 por 100 en 1990. Además, el gobierno elaboró un programa de reformas en el área de la política de ciencia y tecnología que afectó a universidades y centros de investigación (la Ley de Reforma Universitaria se había aprobado en 1983), a los 
objetivos y las herramientas de intervención pública (la aprobación del Plan Nacional de I+D) e incluso a la forma de organización y coordinación de las acciones públicas (la constitución de la Comisión Interministerial de Ciencia y Tecnología - CICYT-). Una pieza clave y, a la vez, elemento simbólico de estas reformas fue la Ley de Promoción y Coordinación General de la Investigación Científica y Técnica (Ley 13/1986), más conocida como Ley de la Ciencia. Mientras que en los ochenta se había producido un crecimiento, en términos reales, de los fondos destinados a los centros de $\mathrm{I}+\mathrm{D}$, aunque a menor ritmo que el crecimiento de los recursos para universidades o empresas, en los noventa se produjo una cierta pérdida general de la relevancia de las actividades de investigación en el contexto político, que llevó al estancamiento, e incluso al declive, de las inversiones públicas y privadas en $\mathrm{I}+\mathrm{D}$, que, como resultado de las políticas de contención del gasto público, afectó especialmente a los centros públicos de $\mathrm{I}+\mathrm{D}$.

\subsection{LA PRIORIDAD POLÍTICA A LA INVERSIÓN EN I+D EN LOS OCHENTA}

España, comparada con otros países como Alemania (2,52 por 100), Francia (2,06 por 100$)$, Reino Unido (2,27 por 100$)$ o incluso Italia $(0,90$ por 100), dedicaba muy poco a investigación a principios de los ochenta (European Commission, 1997). Una de las prioridades de los primeros gobiernos socialistas fue el aumento de los niveles de gasto en I+D hasta estándares europeos, lo que llevó incluso a prometer que se llegaría a un 2 por 100 del PIB. Se produjo un incremento significativo de los fondos públicos destinados a investigación, además de un cambio en sus formas de provisión, con un creciente peso de los mecanismos competitivos para la obtención de la financiación, frente a los mecanismos tradicionales de asignación presupuestaria directa a los centros de investigación.

A pesar de los grandes incrementos de las inversiones públicas en $\mathrm{I}+\mathrm{D}$ durante los años ochenta, se puede observar, en la tabla 1, que el sector gubernamental perdió peso relativo respecto al resto de los sectores. Los créditos presupuestarios gastados en los centros públicos de I+D, en 1980, representaban el 57,2 por 100 del total, mientras que en 1990 descendieron al 32,6 por 100 .

Como consecuencia de este proceso, al final de los años ochenta, los centros públicos de investigación habían aumentado sus niveles de actividad en términos absolutos; sin embargo, en términos relativos habían reducido su peso en el gasto total de I+D español, pasando a representar un 21,3 por 100 en 1990, frente a un 31,6 por 100 del total en 1980 (INE, 2000). Así pues, el crecimiento del gasto público destinado a $\mathrm{I}+\mathrm{D}$ se produjo no tanto en las partidas de transferencia directa a los centros públicos de I+D, sino en la «financiación competitiva», en los fondos destinados a las acciones del Plan Nacional de $\mathrm{I}+\mathrm{D}$ y de otros programas sectoriales de fomento de la $\mathrm{I}+\mathrm{D}$. 


\section{TABLA 1}

Créditos presupuestarios totales para I+D y porcentaje de los fondos que se ejecutan en centros públicos de $I+D$

\begin{tabular}{|c|c|c|c|c|c|c|c|c|}
\hline & \multicolumn{4}{|c|}{$\begin{array}{c}\text { Créditos presupuestarios totales para } I+D \\
\text { (en millones de Ecus, } 1990 \text {, en } \\
\text { paridad de poder de compra) }\end{array}$} & \multicolumn{4}{|c|}{$\begin{array}{l}\text { Porcentaje de los créditos presupuestarios } \\
\text { totales para } I+D \text { que se ejecutan } \\
\text { en el sector gubernamental } \\
\text { (centros públicos de } I+D)\end{array}$} \\
\hline & 1980 & 1985 & 1990 & 1995 & 1980 & 1985 & 1990 & 1995 \\
\hline Alemania & 10.048 & 10.781 & 11.164 & 11.837 & & 31,4 & 35,3 & 37,3 \\
\hline 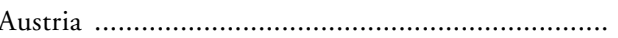 & 461 & 564 & 664 & 897 & & 19,1 & & $19,7(1)$ \\
\hline Bélgica ............ & 726 & 798 & 922 & 1.007 & 14,5 & 14,9 & & 9,7 \\
\hline Dinamarca ........... & 292 & 406 & 596 & 641 & 51,4 & 44,1 & 39,3 & $48,6(1)$ \\
\hline España & 704 & 1.269 & 2.360 & 2.305 & 57,2 & 35,9 & 32,6 & 33,8 \\
\hline 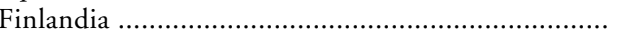 & 306 & 434 & 615 & 731 & & 45,9 & 43,6 & 40,2 \\
\hline 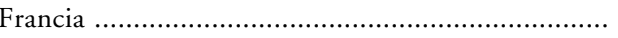 & 8.149 & 11.306 & 12.653 & 10.769 & 38,0 & 39,7 & 42,2 & 43,7 \\
\hline Grecia ..................................................... & 87 & 144 & 196 & 278 & & 71,5 & & 43,1 \\
\hline Holanda & 1.785 & 1.774 & 2.026 & 1.954 & 39,6 & 40,4 & 40,1 & $46,8(3)$ \\
\hline 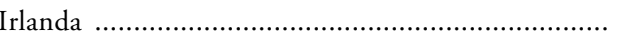 & 119 & 114 & 108 & 179 & & 58,8 & 43,5 & 37,4 \\
\hline 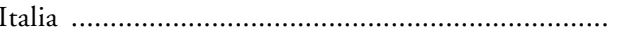 & 2.765 & 4.867 & 6.340 & 5.624 & 46,4 & 41,1 & 36,8 & 35,9 \\
\hline 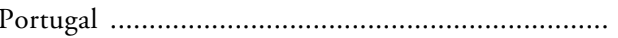 & & 164 & 291 & 467 & & & 40,9 & $32,6(2)$ \\
\hline 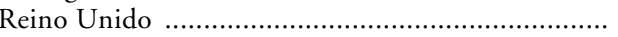 & 6.905 & 8.245 & 7.509 & 7.083 & 44,7 & 35,2 & 31,7 & 37,2 \\
\hline Suecia & 1.337 & 1.510 & 1.628 & 1.638 & & 10,1 & & 11,2 \\
\hline 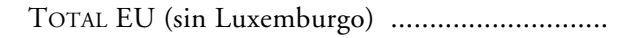 & 33.684 & 42.376 & 47.072 & 45.410 & 37,1 & 33,8 & 34,6 & 35,4 \\
\hline
\end{tabular}

FuENTE: European Commission (1997), Second European Report on S \& T Indicators 1997, Brussels: CEC, EUR 17639, Appendix, s-3. (1) 1993; (2) 1992, y (3) 1994. 
Pero, más allá del compromiso socialista con la investigación, la financiación pública dependía de la relevancia de la $\mathrm{I}+\mathrm{D}$ en la agenda política y de las posibilidades del Presupuesto del Estado, que posteriormente se vio sometido a graves presiones por el aumento del coste de la deuda pública y de las prestaciones por desempleo.

\subsection{LOS CENTROS PÚBLICOS DE INVESTIGACIÓN Y LAS REFORMAS}

Durante la dictadura franquista los centros públicos de $\mathrm{I}+\mathrm{D}$ eran los únicos que desarrollaban investigación en España, dado que «la mayor parte de la investigación científica se lleva a cabo en centros o instituciones gubernamentales [y] desde el punto de vista financiero el 85 por 100 de los costes totales de investigación del país se canalizan a través de siete centros de I+D»(OECD, 1964).

Los centros públicos de investigación españoles eran instituciones establecidas por los Ministerios y financiadas por medio de los Presupuestos Generales del Estado. La mayoría de sus empleados tenían la condición de funcionarios (aunque también había contratados laborales) y sus actividades de investigación se llevaban a cabo atendiendo a los intereses ministeriales.

La actuación de los centros estaba basada en el principio de "delegación» (Rip, 1994), pero los centros funcionaban bajo un sistema de autoridad jerárquica de tipo burocrático. La asignación de los recursos a los diferentes proyectos, unidades o individuos se producía por el criterio de autoridad administrativa de los directores, que en la mayoría de los casos eran directores generales designados por el Ministerio. Apenas había otras fuentes externas de financiación y, en algunos casos, la dependencia ministerial era tan grande que al centro no se le permitía aceptar financiación externa (bien fuese por medio de contratos o de becas).

Frente a este modelo se plantearon reformas institucionales y organizativas que afectaron al entorno y a los propios centros de investigación. Las transformaciones del entorno fueron la consecuencia de un diseño político intencional, con el objetivo de reorganizar la acción del Estado en favor de la $\mathrm{I}+\mathrm{D}$ y, posteriormente, de los cambios en el contexto económico de la actividad pública de investigación.

La Ley de la Ciencia se plasmó en un sistema de política científica construido sobre un Plan Nacional de I+D y bajo una autoridad interministerial: la CICYT. Esta Ley definió nuevas reglas, instituciones y organizaciones del campo de la política científica y tecnológica. El entorno de la I+D se modificó gracias a la presión por alinear las agendas de investigación de universidades y centros de $\mathrm{I}+\mathrm{D}$ con las necesidades económicas y sociales por medio de la «investigación priorizada», "la competencia por los fondos de investigación» como mecanismo básico de financiación (Sanz Menéndez et al., 1993; Sanz Menéndez, 1995 a y b) y la promoción de incentivos para incrementar la "financiación externa», bien pública (proveniente de programas nacionales, sectoriales, regionales o europeos) o privada (por medio de contratos con empresas para la I+D conjunta o la provisión de servicios científico-técnicos). 
En la Ley de la Ciencia los centros públicos de I+D eran también un instrumento del Estado, para lo cual se planteban reformas y se les definía como medios para la coordinación de la $\mathrm{I}+\mathrm{D}$. Las normas referidas a los centros públicos de investigación trataban de homogeneizar situaciones y dotarlos de flexibilidad, para promover su coordinación con las prioridades nacionales del Plan. La Ley identificó seis organismos públicos de investigación (OPIS) ${ }^{6}$ bajo dependencia ministerial directa, que quedaron definidos como sujetos de algunos principios de organización y de acción comunes. Las regulaciones más importantes afectaron a la gestión económica, la flexibilidad para contratar investigadores no funcionarios y las posibilidades de creación de nuevos incentivos económicos: a) Los seis OPIS (más tarde se unieron otros) tenían reconocida su condición de «organismos autónomos de carácter comercial ${ }^{7}$, aunque manteniendo su dependencia de los Ministerios correspondientes, lo que les permitía obtener financiación externa (y generar créditos presupuestarios con ella), procedente tanto de fondos competitivos estatales o europeos como del establecimiento de convenios o contratos con empresas. La Ley hizo a los OPIS más flexibles para enfrentarse a los cambios, abriendo la puerta claramente a la diversificación de las fuentes de financiación de la investigación. b) Además, se les otorgaron mecanismos para la contratación de investigadores para la ejecución de proyectos de I+D (luego sometida a autorización en número y precio por los Ministerios de Administraciones Públicas y de Economía y Hacienda). c) La Ley, en su artículo 18.2, también aprobó la posibilidad (sujeta a posterior regulación de los Ministerios de Economía y Hacienda y de Administraciones Públicas) de que algunos de los ingresos de carácter comercial, derivados de los contratos firmados con entidades públicas o privadas para la ejecución de trabajos científicos o de asesoramiento técnico, pudieran transferirse a los investigadores individuales como complemento de productividad; por tanto, se abría la puerta a un sistema de incentivos individuales en esos centros de investigación que funcionaban bajo las reglas retributivas de la función pública.

Las nuevas regulaciones incrementaron el número de respuestas disponibles para los directivos y los investigadores dentro de las organizaciones de I+D. Las condiciones para un aumento en la autonomía de los centros y una mejora de su gestión estaban dadas. Estos cambios contribuyeron a fortalecer su autonomía decisional respecto a sus Ministerios de tutela y de los investigadores individuales respecto a los directores, pero con diferencias entre los centros. Sin embargo, usar y defender esa autonomía era algo que los centros tenían que decidir frente a sus entornos ministeriales.

Además de cambios de algunas de las regulaciones financieras y adminis-

${ }^{6}$ Éstos fueron el CSIC, CIEMAT, IGME, INTA, IEO e INIA.

7 La Ley 6/1977, de 14 de abril, de Organización y Funcionamiento de la Administración General del Estado, en su Título III, sobre los «Organismos Públicos», eliminó la categoría específica de "Organismos Autónomos de Carácter Comercial» (OACC) y pasó a designarlos simplemente como "Organismos Autónomos» (arts. 41 a 52). Posteriomente, la normativa presupuestaria permite la incorporación de los ingresos comerciales extrapresupuestarios que se hacía anteriomente en los OACC. 
trativas bajo las cuales los centros podían operar, la Ley contribuyó a institucionalizar un nuevo "campo organizativo" (DiMaggio y Powell, 1983) de tipo normativo: el de la investigación. Por otro lado, las prácticas comunes que comenzaron a desarrollarse crearon una población de organizaciones singular: los organismos públicos de investigación ${ }^{8}$.

Así pues, cuando se produjo un descenso en las disponibilidades de financiación en los noventa, que se analizará en el apartado siguiente, los OPIS tenían ya algunos instrumentos para adaptarse. El entorno general de las actividades de investigación había cambiado drásticamente.

Los centros públicos de investigación' que se han elegido como objeto de este análisis se presentan en la tabla 2. Son los más importantes, los de mayor dimensión y con una larga trayectoria, aunque bien es verdad que existen otros centros grandes (como el Centro Nacional de Meteorología, etc.) que no se han incluido, bien porque son simples unidades de la Administración Pública o porque no tienen la naturaleza de OPIS y, por tanto, no tienen la posibilidad de adaptarse por la vía de obtener financiación externa.

Los centros, en su mayoría, son sólo ejecutores de investigación; sin embargo, en dos casos persisten funciones de gestión de fondos de investigación de naturaleza competitiva que están incluidos en sus presupuestos. El ISCIII gestiona, desde 1997, el Fondo de Investigaciones Sanitarias (FIS), que representa del orden de un tercio del presupuesto total y que se destina a financiar investigación competitiva en biomedicina y salud, especialmente en hospitales. El INIA ha venido gestionando tradicionalmente un fondo de investigación agraria, destinado esencialmente a los centros del denominado «sistema INIA», centros transferidos $\mathrm{u}$ organizados por las Comunidades Autónomas, y que también representa aproximadamente un tercio de los presupuestos del INIA. Recientemente, el FIS ha determinado la prohibición de competir a los centros del ISCIII, mientras que los centros del INIA pueden competir por fondos de sus programas, que son considerados como fondos externos ${ }^{10}$.

${ }^{8}$ El desarrollo del campo organizativo y la consolidación de la población se verían reforzados posteriomente con la incorporación al mismo de otros centros de investigación, con la creación de la Comisión de Coordinación Funcional de los OPIS en 1996 y con el posterior traspaso de cinco de ellos a la tutela del nuevo Ministerio de Ciencia y Tecnología, ya en mayo de 2000, bajo la recién creada Secretaría General de Política Científica.

9 Para más información, véanse, por ejemplo, Alonso, Fernández y Sanz Menéndez (2001), López Facal y Represa (1998) o Muñoz, Santesmases y Espinosa (1999).

${ }^{10}$ Estos centros han dependido tradicionalmente del mismo Ministerio; sin embargo, algunos han cambiado recientemente. Por ejemplo, el IGME era parte del Ministerio de Industria y Energía y, aunque pasó a Medio Ambiente en 1996, en la segunda legislatura del gobierno del Partido Popular ha sido traspasado a Ciencia y Tecnología, junto con los centros que dependían históricamente de Educación (el CSIC) y de Agricultura (el INIA y el IEO), así como el CIEMAT, que pertenecía al desaparecido Ministerio de Industria y Energía. Además, hay que señalar que uno de ellos, el CEDEX, ni siquiera se define de forma completa como un centro de investigación, dado que en su presupuesto ordinario menos del 20 por 100 de sus actividades aparecen reflejadas como I+D, dominando la prestación de trabajos técnicos en el campo de las obras públicas e ingeniería civil. 
TABLA 2

Centros públicos de $I+D$ y sus caracteristicas

\begin{tabular}{|c|c|c|c|c|c|c|}
\hline Acrónimo & Nombre & $\begin{array}{l}\text { Año de } \\
\text { creación }\end{array}$ & $\begin{array}{c}\text { Personal } \\
2000\end{array}$ & $\begin{array}{c}\text { Ministerio } \\
\text { de dependencia } \\
\text { hasta abril } 2000\end{array}$ & $\begin{array}{c}\text { Ministerio } \\
\text { de dependencia } \\
\text { (junio 2000) }\end{array}$ & $\begin{array}{c}\text { Areas científicas y tecnológicas } \\
\text { de competencia }\end{array}$ \\
\hline CSIC & $\begin{array}{l}\text { Consejo Superior de Investiga- } \\
\text { ciones Científicas }\end{array}$ & 1939 & 9.630 & Educación y Cultura & Ciencia y Tecnología & $\begin{array}{l}\text { Todos los campos de investiga- } \\
\text { ción básica y muchos aplicados }\end{array}$ \\
\hline CIEMAT & $\begin{array}{l}\text { Centro de Investigaciones Ener- } \\
\text { géticas, Medioambientales y } \\
\text { Tecnológicas }\end{array}$ & 1948 & 1.226 & Industria y Energía & Ciencia y Tecnología & $\begin{array}{l}\text { Energía nuclear, energías alter- } \\
\text { nativas y medio ambiente }\end{array}$ \\
\hline INIA & $\begin{array}{l}\text { Instituto Nacional de Investiga- } \\
\text { ción y Tecnología Agraria y } \\
\text { Alimentaria }\end{array}$ & 1971 & 530 & $\begin{array}{l}\text { Agricultura, Pesca y } \\
\text { Alimentación }\end{array}$ & Ciencia y Tecnología & $\begin{array}{l}\text { Agricultura, ganadería, fores- } \\
\text { tal y alimentación }\end{array}$ \\
\hline IEO & $\begin{array}{l}\text { Instituto Español de Oceanogra- } \\
\text { fía }\end{array}$ & 1914 & 489 & $\begin{array}{l}\text { Agricultura, Pesca y } \\
\text { Alimentación }\end{array}$ & Ciencia y Tecnología & $\begin{array}{l}\text { Oceanografía, acuicultura, pes- } \\
\text { ca y medio marítimo }\end{array}$ \\
\hline IGME & Instituto Geominero de España & 1859 & 398 & Medio Ambiente & Ciencia y Tecnología & $\begin{array}{l}\text { Geología, minería, medio am- } \\
\text { biente, aguas }\end{array}$ \\
\hline INTA & $\begin{array}{l}\text { Instituto Nacional de Técnica } \\
\text { Aeroespacial «Esteban Terradas» }\end{array}$ & 1942 & 1.288 & Defensa & Defensa & $\begin{array}{l}\text { Aeronáutica, espacio, electró- } \\
\text { nica, comunicaciones }\end{array}$ \\
\hline ISCIII & Instituto de Salud «Carlos III» & 1986 & 839 & Sanidad y Consumo & Sanidad y Consumo & Biomedicina y salud humana \\
\hline CEDEX & $\begin{array}{l}\text { Centro de Estudios y Experi- } \\
\text { mentación de Obras Públicas }\end{array}$ & 1957 & 735 & Fomento & Fomento & $\begin{array}{l}\text { Obras públicas, construcción, } \\
\text { hidrografía, medio ambiente }\end{array}$ \\
\hline
\end{tabular}




\subsection{LOS CAMBIOS EN EL ENTORNO EN LOS NOVENTA:}

LA CRISIS DE FINANCIACIÓN EN LOS CENTROS PÚBLICOS DE INVESTIGACIÓN

La coyuntura favorable para la I+D cambió drásticamente en los años noventa y se inició un período de estancamiento relativo del esfuerzo público en $\mathrm{I}+\mathrm{D}$, que parece haber mejorado desde $1997^{11}$. La figura 1 muestra la evolución de los Presupuestos Generales del Estado destinados a I+D en pesetas constantes.

\section{FIGURA 1}

\section{Gastos de I+D (función 54) en los Presupuestos Generales del Estado (En millones de pesetas constantes de 1996)}

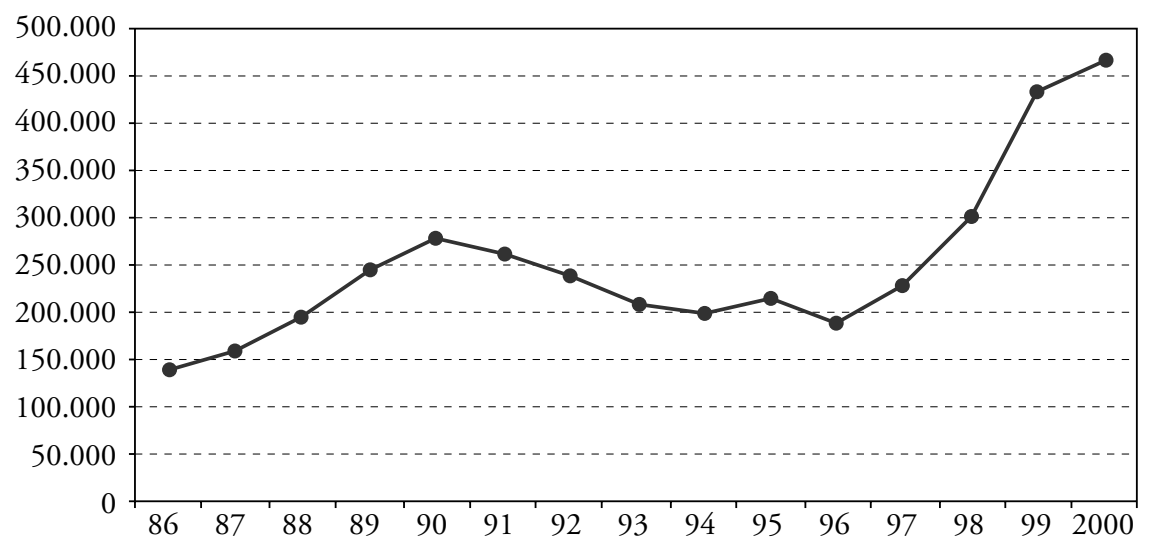

FuENTE: Presupuestos Generales del Estado, varios años. Créditos iniciales.

Del mismo modo que la evolución presupuestaria empeoró a principios de los noventa, también lo hizo la financiación directa a los centros de investigación desde los Ministerios, que se estancó e incluso disminuyó, en términos reales $^{12}$, y que sólo mejoró ligeramente a partir de 1997.

11 Hay que decir que el asunto es polémico, pues el crecimiento del conjunto de la función 54, que incluye los gastos de I+D en los Presupuestos Generales del Estado, se ha producido en el capítulo 8, bajo la modalidad de créditos reembolsables que se dirigen esencialmente a las empresas, y que ha pasado a representar casi el 50 por 100 del total de la financiación pública. Así pues, la mejora y el crecimiento del gasto público en favor de la I+D, desde 1997, han tenido un destinatario y beneficiario directo: las empresas.

12 En los presupuestos ordinarios de ingresos, también llamados administrativos, hay dos componentes principales: las "transferencias corrientes e inversiones» (caps. 4 y 7) provenientes de los Ministerios de tutela y los ingresos propios derivados de su patrimonio, fondos de maniobra, etc. Este presupuesto inicial aparece recogido en los Presupuestos Generales del Estado que 


\section{FIGURA 2}

Evolución de los presupuestos ordinarios de gastos de los OPIS (En pesetas constantes de 1996) (Números índices, Base 1988=100)

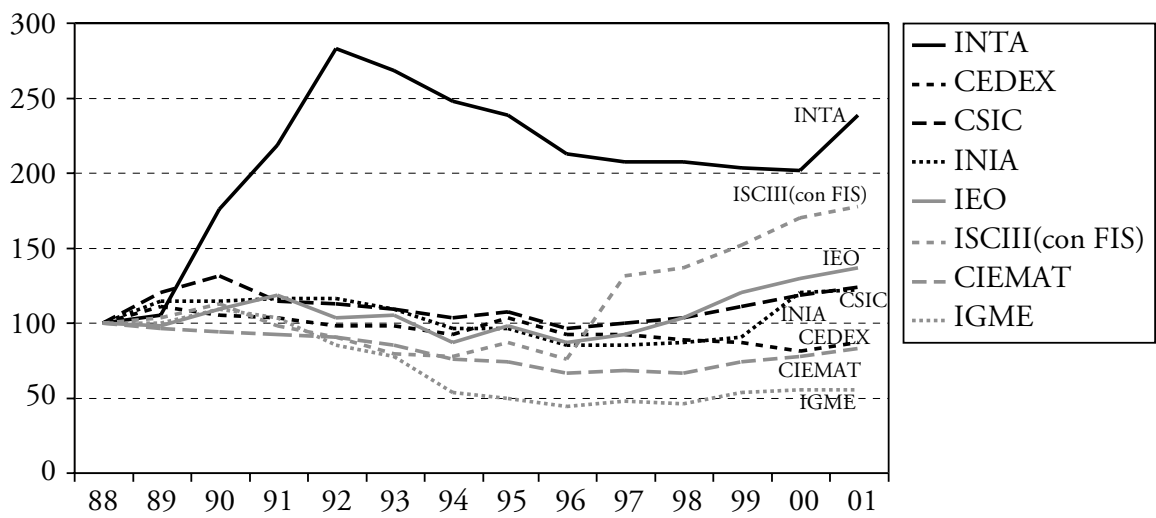

En los últimos años algunos de los centros (IEO, INIA, CSIC e ISCIII) han recuperado, en términos reales, los niveles presupuestarios de 1988, quedando otros OPIS (CIEMAT, IGME y CEDEX) todavía por debajo de los niveles de 1988. Hay que señalar que la fuerte subida de los presupuestos del Instituto de Salud Carlos III se debe a que, a partir del ejercicio de 1997, se incorporó a los presupuestos del Instituto la dotación del Fondo de Investigaciones Sanitarias (FIS), con casi 5.000 millones de pesetas, y que anteriormente aparecía en los presupuestos del Ministerio de Sanidad.

Para observar con mayor claridad los efectos de la crisis de financiación pública basada en las transferencias presupuestarias directas de los Ministerios de tutela se puede ver, en la figura 3, la evolución de las tasas interanuales de variación de las transferencias en el apartado de los ingresos de los OPIS ${ }^{13}$.

De forma general, entre 1992 y 1998 las tasas anuales de variación de los presupuestos se modificaron por debajo de los niveles de la inflación. Sin embargo, habría que matizar la intensidad de las dificultades de financiación en los OPIS. El INTA tuvo un aumento extraordinario del presupuesto entre 1989 y 1992, que le permitió poner en marcha un programa de minisatélites que tenía como objetivo dotar a España de capacidad de lanzamiento y pro-

las Cortes aprueban cada año. Por otro lado, existe un segundo bloque de gastos que se financia con los ingresos derivados de la "actividad comercial» (ventas) que bien se incorporan al presupuesto, con generación de crédito, o bien se gestionan en un presupuesto diferenciado como operaciones comerciales. En todo caso, hay que señalar que no existe una práctica contable homogénea y estandarizada en los diversos centros objeto de estudio.

${ }_{13}$ Con excepción de las correspondientes al CEDEX. 
ducción; esto facilitó los créditos presupuestarios para la expansión de su actividad, precisamente en los años de mayor crisis. En este caso, la asociación con los objetivos del Ministerio de Defensa se convirtió en una ventaja para el aumento de los presupuestos y de las transferencias netas.

\section{FIGURA 3}

Tasas de variación interanual de las transferencias en el presupuesto de ingresos (En términos reales)

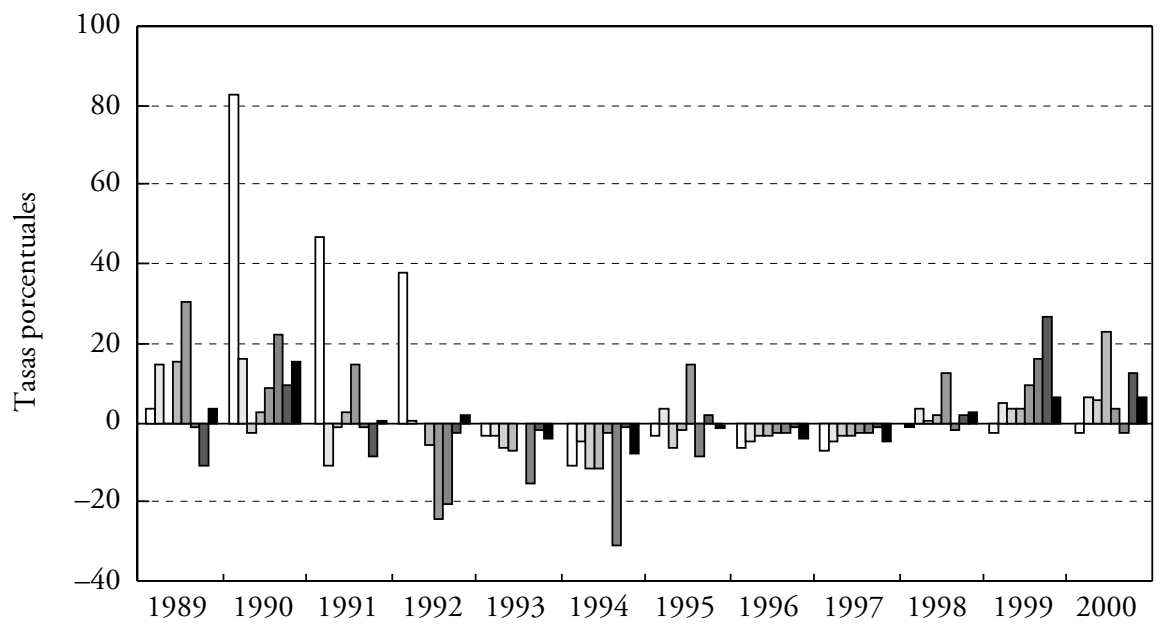

INTA $\square$ CSIC $\square$ CIEMAT $\square$ INIA $\square$ IEO $\square$ IGME $\square$ ISCIII(sin FIS)

8 OPIS

FUENTE: Elaboración propia sobre datos de CICYT: Flujos financieros en $I+D$.

En definitiva, los OPIS sufrieron una reducción significativa en los noventa de la contribución financiera directa de la Administración General del Estado a su funcionamiento. Además, corrieron una suerte diferenciada dependiendo de en qué Ministerio estaban. Los OPIS dependientes del Ministerio de Industria sufrieron mayores recortes relativos, frente a los dependientes de Defensa, Agricultura y Educación, que sortearon la situación. La dependencia ministerial es un elemento diferencial, dado que el proceso que determina los «recortes presupuestarios» se concreta en cada Ministerio, trasladando éstos de forma diversa a los diversos servicios del mismo. En esos años, la ideología "pro-empresa" y de reducción de la ejecución directa de la investigación era defendida por el Ministerio de Industria, que no quería disponer de centros propios, sino promover la $\mathrm{I}+\mathrm{D}$ en la industria privada. 


\section{LA BÚSQUEDA DE FINANCIACIÓN EXTERNA COMO RESPUESTA A LOS PROBLEMAS}

Las transformaciones organizativas e institucionales y, sobre todo, el estancamiento de los créditos presupuestarios transferidos directamente a los centros públicos de investigación se convirtieron en presiones para el cambio. ¿Hasta qué punto este nuevo entorno produjo una respuesta adaptativa (March, 1994) de los centros de investigación? Las respuestas al nuevo entorno variaron significativamente, tanto en el tipo de estrategia adoptada como en la intensidad de la reacción. Unos centros comenzaron a diversificar sus fuentes de ingresos, aumentando la importancia de las fuentes externas sobre el total de gastos de la organización, mientras que otros, por el contrario, apenas buscaron financiación exterior, a pesar de las oportunidades creadas por las nuevas regulaciones. Así, algunos centros obtienen hoy en día casi el 50 por 100 de su presupuesto total de gastos de fuentes distintas de las transferencias directas de los Presupuestos Generales del Estado, mientras que otros desarrollan sus actividades casi en los límites financieros impuestos por las transferencias de sus Ministerios.

Hemos utilizado la transformación de la estructura de financiación de los centros como indicador, a la vez, del tipo de respuesta a los cambios y del grado de adaptación de los mismos al nuevo entorno económico. La obtención de financiación "externa» ${ }^{14}$ había comenzado antes de los noventa para algunos de los OPIS; sin embargo, lo que nos interesa es, en primer lugar, determinar cómo se explica la evolución de la financiación externa y hasta qué punto fue el resultado o la reacción a las dificultades y reducciones de la financiación directa que se observa.

Si todas las condiciones de los centros fuesen idénticas, se podría esperar que a mayor descenso en la asignación de los presupuestos procedentes de los Presupuestos Generales del Estado, mayor sería el incentivo de la organización para mover su atención a las fuentes no presupuestarias. Sin embargo, esa correlación no es lineal ni directa; el porcentaje de la financiación externa es muy diverso entre los centros de investigación y lo que se pretende aquí es explicar la variación en el grado de adaptación organizativa, medida como la proporción comparada del total del gasto que no procede de las transferencias de los PGE. Las fuentes principales de esos fondos no transferidos directamente desde los Presupuestos Generales del Estado son muy diversas, tales como ingresos patrimoniales, remanentes de caja, etc., e incluso una fuerte actividad de "venta» de servicios científico-técnicos o de investigación, a veces como

${ }_{14}$ El tipo y grado de intensidad de la respuesta adaptativa a los problemas de financiación se analiza a través de una proxy que es el porcentaje del presupuesto final de gastos que se financia con recursos externos procedentes de las "operaciones comerciales», los recursos no provenientes de transferencias directas de los PGE al principio de cada año. El estrés lo medimos por la evolución de estas transferencias directas (caps. 4 y 7) que aparecen en los PGE de cada Ministerio con destino a los OPIS. 
resultado de convenios, de contratos o de la obtención de financiación competitiva.

Por otro lado, los ingresos extrapresupuestarios son, a veces, producto de la agregación de múltiples iniciativas de investigadores individuales (por ejemplo, en el caso del CSIC), mientras que en otros son el resultado de la acción institucional de los directivos de los centros o de las demandas de los Ministerios que, por medio de convenios institucionales, explotan las capacidades de los centros de investigación (como es el caso del IGME o del CEDEX) a través de la prestación de servicios o dictámenes, muchas veces requeridos legalmente. Dada la existencia de demandantes externos a la Administración Pública, o de un mercado de sus actividades de investigación, los directivos de los OPIS pueden promover la venta de sus capacidades investigadoras, aunque en algunos casos se ejerza casi en posición monopolística, situación que se da, por ejemplo, en el CIEMAT o el INTA, que en determinados campos - energía o aeronáutica- son los únicos suministradores potenciales en España. Tampoco se puede olvidar que a veces el centro, disponiendo de autonomía organizativa para el desarrollo de su misión investigadora, es un «instrumento» de la política del Ministerio en su propia área de funcionamiento (el caso del ISCIII en el área de sanidad y, con anterioridad, del INIA en el área agraria), lo que seguramente no empuja hacia reacciones adaptativas tendentes a la búsqueda de la financiación externa.

El grado de estancamiento o retroceso en términos de pesetas constantes de las transferencias directas del Estado no explica, por sí solo, los niveles de obtención de financiación externa, ni el porqué algunos OPIS han desarrollado extraordinariamente la obtención de financiación exterior para continuar con sus actividades de I+D, mientras que otros no. Por ejemplo, entre los centros que han sufrido en la década de los noventa mayor estancamiento o disminución de las transferencias, como fueron IGME, CEDEX, CIEMAT e INIA, las estrategias de adaptación varían. Mientras que CEDEX e IGME optan por estrategias de prestación de servicios a la Administración Pública y son retribuidos por medio de convenios que resultan en ingresos externos, el CIEMAT desarrolla una estrategia basada en la obtención de fondos externos, pero fundamentalmente de la venta al sector privado, en sectores donde sus capacidades de $\mathrm{I}+\mathrm{D}$ son casi monopolísticas. Por otro lado, el INIA, en el proceso de reducción de su dependencia ministerial, adoptó una estrategia basada en la agregación de las conductas de los investigadores de base y en la búsqueda de financiación competitiva.

En un sentido contrario, entre los centros mejor tratados en la evolución de las transferencias directas desde los PGE, al menos durante los años críticos, el INTA se presenta como uno de los más activos en la búsqueda de fondos externos, lo mismo que el CSIC y, en menor medida, el IEO. Sin embargo, un centro razonablemente sostenido con las transferencias, como el ISCIII, apenas ha reaccionado incrementando la financiación exterior.

Así pues, a pesar de que los centros se enfrentaron a cambios relativamente 
similares del entorno aunque con diversas intensidades, ante la diversidad de resultados en términos de los niveles de financiación externa necesitamos explicaciones adicionales. En lo que sigue mantenemos que las trayectorias institucionales ${ }^{15}$ aún explican mucho de la respuesta y conducta organizativa y de los investigadores, frente a unas transferencias directas decrecientes. Argumentamos que la obtención de financiación externa por los centros es el resultado final de un complejo proceso de interacciones entre la autonomía de los investigadores frente al centro, asociada con su dependencia de los recursos del mismo y de la existencia de incentivos económicos y de carrera, y de la autonomía de la organización con respecto al sistema político. Las bases de ambos tipos de autonomía son de carácter institucional y organizativo. La diversidad de los resultados es atribuible, por una parte, a la estructura normativa y de recursos dentro de la cual se sitúan las decisiones de los investigadores dentro de la organización y, por otra, a la estructura de autoridad en la que esta última se encuentra dentro de su Ministerio, combinada con las posibilidades de acceso a mercados alternativos de usuarios o demandantes de investigación.

\section{1. ¿POR QUÉ LAS REACCIONES ADAPTATIVAS SON DIVERSAS? LA «AUTONOMÍA» COMO FACTOR EXPLICATIVO Y SUS COMPONENTES}

Los centros públicos de investigación se han visto afectados por presiones similares en favor del cambio; sin embargo, la proporción de financiación externa es muy distinta entre nuestros casos. Posteriormente describiremos cómo unos centros han afrontado el problema con una estrategia de adaptación activa, colectiva o individualmente, mientras otros se han acomodado pasivamente a la nueva situación o han esperado la asignación de misiones por los Ministerios de tutela, pero en esta sección queremos explorar los factores que explican esta diversidad de respuestas adaptativas de los centros ante cambios en el entorno económico.

La autonomía de la organización respecto del sistema político, que depende de la fortaleza de las relaciones con los Ministerios de tutela, determina el margen de maniobra para la dirección de los centros públicos; sobre esta relación de autonomía influye la naturaleza del trabajo de investigación o servicio de los centros, que posibilita, en distinta medida según las áreas de $\mathrm{I}+\mathrm{D}$, el establecimiento de vínculos autónomos de las misiones que los Ministerios asignen, con los usuarios y demandantes de investigación.

En segundo lugar, la autonomía de los investigadores con respecto a la

15 La dinámica diversa de transformación en los centros de investigación puede explicarse desde una aproximación institucionalista, y con variables organizativas, asumiendo modelos que reflejan la relevancia de los procesos históricos, esto es, path dependency (David, 1985; Arthur, 1983), e incluso la inercia organizativa (Hannan y Freeman, 1984). 
organización viene dada por la posibilidad de desarrollar estrategias individuales, basadas en la existencia de una limitada dependencia de los recursos colectivos (infraestructuras y equipamiento) que gestiona la organización y, en el caso extremo, por la existencia de incentivos individualizados, que debilitan los esquemas tradicionales de autoridad en la organización. Ambos tipos de autonomía no están necesariamente unidos.

Por una parte, la carencia, de forma simultánea, de autonomía organizativa e individual en algunos OPIS nos presenta una situación de fuerte dependencia del centro tanto a nivel interno como externo. La dependencia completa crea un modelo "respuesta pasiva» basado en la aceptación de los cambios en el entorno de modo más o menos conformista, esperando que el Ministerio de tutela o la Administración favorezca la solución de los problemas que el centro tiene. Por otra parte, puede darse la situación en que un centro disponga de autonomía organizativa respecto del sistema político, pero cuyos investigadores tienen una autonomía limitada en el seno de la organización, bien porque carecen de incentivos individuales para comportarse de forma autónoma y reforzar sus grados de independencia por el procedimiento de la búsqueda de fondos, o bien porque dependen de los recursos organizativos para llevar a cabo su actividad investigadora y los fondos que pudiesen obtener no cubrirían en ningún caso el coste de los equipos necesarios. El tipo de respuesta de los centros de investigación que están en esta situación será fundamentalmente el resultado de las estrategias y acciones de los directivos, cuyo control sobre los recursos tangibles de la organización fortalece su posición de autoridad; la respuesta adaptativa será activa, pero en este caso de carácter colectivo, ya que la búsqueda de financiación externa toma aquí la forma de función directiva.

Por último, si existe autonomía de la organización respecto del sistema político y, además, o bien se han desarrollado sistemas de incentivos individuales que promueven la autonomía de los investigadores respecto de la organización, o bien éstos no dependen de los recursos organizativos para investigar, podemos predecir que, a partir de estas dos dimensiones de la autonomía, la respuesta esperable respecto de los cambios del entorno será la adaptación activa basada en las estrategias individuales.

\subsubsection{La autonomía politica del centro de investigación respecto del Ministerio}

Las autoridades ministeriales tienen una relación con los OPIS que se expresa en la regulación general, en el nombramiento de los directivos y en la determinación de los volúmenes de financiación anual que se transfieren directamente. Por otro lado, los centros disponen de un marco regulador que les permite la obtención de financiación externa y su incorporación a los presupuestos para llevar adelante proyectos y actuaciones en investigación.

Los Ministerios tienen una pauta histórica de relación con los centros y los primeros han venido "demandando" de éstos la producción de conocimiento, 
asesoramiento técnico o servicios que son necesarios para el normal desempeño de sus actividades. Si el Ministerio de tutela "promueve» este tipo de relación, es difícil que el director del centro pueda negarse; lo que sí puede hacer es demandar los recursos necesarios para el desarrollo de estas misiones, para lo cual el Ministerio transferirá más recursos por medio de la compra de servicios, la firma de convenios o el encargo de trabajos.

Así pues, las autoridades ministeriales deben aprobar, permitir o promover el grado de autonomía de su propio centro. La fundamentación de tal movimiento por parte de los decisores de los Ministerios puede ser diversa: abandonar la vieja idea de la subordinación del centro a las necesidades exclusivas del Ministerio, la aceptación de las nuevas ideas de la coordinación de la política de ciencia y tecnología o, simplemente, los esfuerzos para solucionar las limitaciones que imponen las restricciones presupuestarias; también podría ser resultado de la consolidación de un sector privado capaz de proveer al Ministerio de esos mismos servicios ${ }^{16}$.

Así pues, nuestro argumento predice que cuanto menor es la autonomía de los centros del sistema político, menores los incentivos que la dirección de éstos tendrá para adaptarse a las nuevas presiones ambientales y buscar financiación fuera de la Administración Pública. En nuestro caso, la predicción sería que el CSIC o el CIEMAT, que tienen mayor autonomía, se moviesen a la autofinanciación como estrategia. En el lado opuesto, IGME o CEDEX, históricamente muy ligados a sus Ministerios y a sus demandas de conocimiento, tendrán más dificultades para moverse en la dirección de nuevas estrategias de financiación fuera del sector público.

Hay otros factores que influyen en los directores de los centros a la hora de movilizar a sus investigadores o hacer uso de su autoridad para favorecer la búsqueda de financiación exterior. La actividad concreta y sustantiva de los OPIS crea algunas especificidades que pueden influir en sus oportunidades de adaptar sus estrategias de financiación. Esta variable interviene en el margen de maniobra que el centro tiene con respecto al Ministerio o que éste está dispuesto a otorgarle. En este caso, nuestro argumento predice que la adaptación a las nuevas estrategias de financiación será más intensa en los centros de investigación que tienen a su disposición, por su área tecnológica o de investigación, programas especializados de $\mathrm{I}+\mathrm{D}$ internacionales o mercados donde "vender" sus servicios y competencias.

Por tanto, el primer tipo de autonomía que estamos analizando, la organizativa, viene dada por la dependencia política y por las oportunidades externas disponibles para financiar específicamente las actividades de I+D en su área de competencia.

Los OPIS cuya misión, por razón de su trayectoria institucional, está centrada en proveer a su respectivo Ministerio de asesoramiento técnico o de servicios tenderán a prestar menos atención a los fondos externos. Los directivos de

${ }_{16}$ Esto último genera otro tipo de problemas que se derivan de la necesidad de garantizar la independencia del juicio científico o experto. 
estas organizaciones no encuentran ventajas en competir por los recursos, dado que estos centros no serán juzgados por el incremento o mejora de su actividad investigadora, sino por el grado de cumplimiento de una misión delegada. En consecuencia, los ingresos de la organización pasan a ser dependientes de la «buena voluntad» de los responsables ministeriales. La financiación externa representará posiblemente una parte reducida de los ingresos de la organización.

En el lado opuesto, a los OPIS que desarrollan una misión general les resulta más ventajoso incrementar sus ingresos externamente. En esos casos los centros concentran la mayor parte de sus actividades en la investigación y pueden caracterizarse como productores de conocimiento. Las oportunidades para la financiación externa de los centros varían, gracias a la existencia de oportunidades específicas, tales como grandes programas de $\mathrm{I}+\mathrm{D}$ - como el programa de investigación nuclear (EURATOM) — , contratos de la Agencia Espacial Europea o para desarrollos de uso militar, o pequeños programas de investigación marina o pesquera, pero grandes en relación al tamaño del centro. Aplicando el argumento a nuestros casos, podemos esperar que haya más respuesta activa en las estrategias de financiación del CIEMAT, INTA o IEO que en el resto de los centros.

Las diferencias en la naturaleza de la misión investigadora suponen, por último, distintos requerimientos en términos de costes $\mathrm{y}$, por tanto, de necesidades de financiación. Esas áreas que necesitan mayores niveles de inversión y/o financiación para llevar a cabo sus actividades tendrán más incentivos para buscar recursos externos que aquellas áreas de investigación que no se encuentran en esta situación; de esta dependencia puede surgir una estrategia de tipo colectivo en los centros en los que esto ocurre.

\subsubsection{La autonomía de los investigadores: los incentivos y la dependencia relativa de los recursos de la organización}

El segundo elemento en la explicación de la diversidad de respuestas y estrategias de financiación se refiere a la estructura de incentivos individuales o grupales para la búsqueda de financiación exterior. Ante el problema que supone la disminución de financiación interna disponible, que la respuesta adaptativa consista en mayor o menor medida en diversificar las fuentes, depende también de que las carreras profesionales y las retribuciones salariales se asocien a determinadas conductas. La obtención de financiación externa enfrenta a las organizaciones a un problema de acción colectiva o de autoridad como método de acción.

Desde Merton se está de acuerdo en que el ethos científico puede empujar al investigador a esforzarse en su trabajo; sin embargo, los análisis modernos de los sistemas de incentivos individuales y los sistemas retributivos ayudan a entender mejor el compromiso de los científicos para atraer fondos externos y lo asocian a la existencia de recompensas relacionadas con los resultados; los ingresos de los investigadores y sus carreras son los determinantes esenciales de sus resultados de investigación (Weber, 1919; Konrad y Pfeffer, 1990; Gómez-Mejía y Balkin, 1992). 
Si los directores de los OPIS (e incluso los responsables políticos) están interesados en incrementar la financiación externa, los sistemas de incentivos deben favorecer que sus investigadores soliciten financiación competitiva, que complemente su compromiso con la investigación, al margen de la autoridad formal que los directores de los centros tienen sobre ellos; de modo, que se alinean los intereses individuales con los de la organización en su conjunto. La situación no es simple porque en los centros públicos de $\mathrm{I}+\mathrm{D}$ los investigadores tienen con frecuencia el estatus de funcionario, y se les aplican las regulaciones de los mismos para retribuciones, nombramientos y carreras.

Tienen que existir algunas ventajas económicas o de carrera bajo las nuevas condiciones financieras para que los investigadores individualmente compitan por recursos externos. Si competir por recursos, y solicitar financiación externa, significa exclusivamente conseguir más fondos para la organización, entonces los investigadores tendrán pocos incentivos para invertir esfuerzos en ese sentido, a no ser que dependan fuertemente de los recursos comunes para desempenar su actividad ${ }^{17}$. En este contexto el compromiso que resuelve el problema de acción colectiva se refuerza con el ethos investigador, con la presencia de incentivos específicos de tipo individual y con una baja dependencia del investigador individual de los recursos de su organización por su campo de actividad.

De acuerdo con esto, podemos esperar que los centros más interesados en obtener fondos externos ofrecerán sistemas de retribución y de carrera a sus investigadores ${ }^{18}$. Si los incentivos ayudan a que los investigadores compitan por fondos nacionales, regionales o europeos y por contratos con empresas, el efecto final será un aumento de los niveles de financiación exterior de esos OPIS, que representará un tipo de adaptación activa resultante de la agregación de conductas individuales.

Puede suceder, no obstante, que, por su naturaleza, la actividad investigadora de un determinado centro necesite de un volumen y tipo de recursos y equipamiento que supere la capacidad de obtención de fondos externos de cualquier investigador individual. En tales casos, y siempre que la organización tenga cierta autonomía del primer tipo y acceso a mercados de usuarios distintos de los ministeriales, podemos encontrarnos un aumento de la financiación externa que sea fruto fundamentalmente de la función directiva. En estas circunstancias, los directivos de los centros interesados en obtener fondos externos pueden hacer un uso estratégico de la dependencia de los investigadores individuales para alinear sus intereses con los de la organización. Esta dinámica parece describir los casos de INTA y CIEMAT y se corresponde con el estado de la variable dependiente que hemos identificado como respuesta adaptativa colectiva. En los casos en que esa dependencia sea baja, CSIC, INIA e IEO, la

17 Competir y obtener fondos externos para desarrollar un proyecto de $\mathrm{I}+\mathrm{D}$ personal, sin duda, tiene un impacto en la estructura de autoridad en la organización.

${ }_{18}$ Que en parte son resultado de su capacidad de maniobra política — de autonomía políti$\mathrm{ca}$ - para obtener las autorizaciones necesarias de los Ministerios de tutela. 
respuesta será con más probabilidad de carácter individual, aunque, en los dos últimos casos, en ausencia de sistemas de incentivos individualizados, su nivel será con toda probabilidad mucho menos intenso.

\section{TABLA 3}

Indicadores de la reacción adaptativa de los centros de $I+D$

\begin{tabular}{|c|c|c|c|}
\hline Acrónimo & $\begin{array}{l}\text { Créditos iniciales } \\
\text { del presupuesto } \\
\text { administrativo } \\
\text { del OPI, } 2000 \\
\text { (mill. ptas.) }\end{array}$ & $\begin{array}{l}\text { Porcentaje } \\
\text { de financiación } \\
\text { exterior sobre } \\
\text { el gasto total } \\
\text { del OPI, 1998-99 }\end{array}$ & $\begin{array}{c}\text { Fuentes principales } \\
\text { de financiación exterior } \\
\text { ordenadas por relevancia media. } \\
\text { Diferentes años: } 1996-1999\end{array}$ \\
\hline CSIC & 43.564 & 48 & $\begin{array}{l}\text { Plan Nacional I+D }(40 \%) \\
\text { Programa Marco I+D }(28 \%) \\
\text { Contratos empresas }(17 \%)\end{array}$ \\
\hline CIEMAT & 8.631 & 31 & $\begin{array}{l}\text { EURATOM } \\
\text { Programa Marco I+D (34\%) } \\
\text { Contratos empresas (31\%) }\end{array}$ \\
\hline IGME & 3.729 & 8 & Convenios institucionales \\
\hline INIA & $7.517(*)$ & 21 & $\begin{array}{l}\text { Programa Sectorial Agricultura (31\%) } \\
\text { Plan Nacional I+D }(12 \%) \\
\text { Convenios públicos }(26 \%) \\
\text { UE }(17 \%) \\
\text { Convenios privados }(8 \%)\end{array}$ \\
\hline IEO & 4.946 & 20 & $\begin{array}{l}\text { Programa Marco I+D }(80 \%) \\
\text { Secretaría de Pesca }(12 \%)\end{array}$ \\
\hline INTA & 14.695 & 23 & $\begin{array}{l}\text { Contratos empresas }(30 \%) \\
\text { Contratos públicos }(35 \%) \\
\text { Fondos UE }(8 \%) \\
\text { Otra financiación internacional }(25 \%)\end{array}$ \\
\hline ISCIII & $13.280(* *)$ & $7(* * *)$ & $\begin{array}{l}\text { Plan Nacional de I+D (21\%) } \\
\text { Programa Marco I+D (18\%) }\end{array}$ \\
\hline CEDEX & 5.499 & $6(* * * *)$ & $\begin{array}{l}\text { Convenios con Ministerios } \\
\text { Programa Marco I+D }\end{array}$ \\
\hline
\end{tabular}

$\left(^{*}\right)$ Incluye diversos programas y acciones estratégicas del Plan Nacional de I+D+I (2000-2003) que gestiona el INIA, y que suponen unos 1.500 millones de pesetas, que se gastan mediante convocatorias abiertas a las que sí pueden concursar los investigadores del INIA.

${ }^{(* *}$ Incluye el presupuesto del Fondo de Investigaciones Sanitarias (FIS), que representa unos 5.000 millones de pesetas, al que desde 2000 ya no pueden concursar los investigadores del ISCIII.

$\left.{ }^{* * *}\right)$ La proporción se ha calculado descontando el FIS, al que ya no pueden concurrir los investigadores del propio Instituto de Salud Carlos III; antes de la prohibición, los fondos del FIS representaban el 40 por 100 de la financiación exterior del ISCIII.

${ }^{(* * * *)}$ Para estimar la cantidad del CEDEX se han incluido exclusivamente aquellos presupuestos que aparecen explícitamente como I+D, que, como se ha señalado, representan escasamente el 20 por 100 del total. 
En la tabla 3 se presentan los datos relativos a las reacciones adaptativas de los centros. Vistos los niveles de "autofinanciación» y las «fuentes principales» de esa financiación, al margen de las transferencias directas, se constata que el nivel actual y la evolución de los niveles de respuesta de los diversos centros de investigación son muy variados. El caso del CSIC es extremo, pues ha pasado de una proporción de financiación extrapresupuestaria (operaciones comerciales) del 20 por 100 en 1990 a un 48 por 100 en 1999, lo que significa que por cada peseta que el Estado transfiere al CSIC, sus investigadores son capaces de generar otra para la ejecución de su actividad de investigación. En el extremo contrario se encuentran otros OPIS, como el ISCIII, el IGME o el CEDEX, con niveles muy limitados de financiación externa para sus actividades de I+D.

\subsection{CAMbiOS EN LAS ESTRATEGIAS DE FINANCIACIÓN Y DIVERSIDAD EN LAS RESPUESTAS}

Una vez sugeridos los factores principales que explican la diversidad observada en los grados de respuesta adaptativa de los centros en sus estrategias de financiación: la autonomía política de los OPIS en relación a sus Ministerios de tutela, mediada por la naturaleza de sus misión y su interacción con la disponibilidad de fondos externos, y la autonomía de los investigadores dentro de la organización, posibilitada por la naturaleza de los esquemas de incentivos individuales y su mayor o menor dependencia de los recursos organizativos para su trabajo, vamos a contrastar nuestros argumentos empíricamente (tabla 4). Ya se ha dicho que no todos los centros aumentaron igualmente sus niveles de financiación extrapresupuestaria en respuesta a los cambios del entorno, a pesar de la tendencia general a las restricciones presupuestarias.

¿Qué centros han cambiado sus estrategias y por qué? Los centros que más han adaptado sus estrategias de financiación y, en consecuencia, presentan un nivel más alto de financiación externa, son: CSIC, CIEMAT, INTA, INIA e IEO.

El CSIC es la organización que obtiene más fondos externos (48 por 100 de su presupuesto de gastos). El CSIC representa el tipo de estrategia activa de adaptación (coping), lo que es coherente con nuestro argumento, dado que el CSIC es un centro productor de conocimiento que está implicado en investigación básica y aplicada. En alguna de las áreas que cubre se requieren fuertes niveles de inversión y financiación, mientras que en otras existen mercados para sus resultados de investigación. Podemos deducir un gran interés del CSIC por la financiación externa. Existen en el CSIC sistemas de incentivos basados en esquemas retributivos individualizados y recompensas de carrera que han tenido un efecto positivo en el nivel de financiación externa de la institución durante los años noventa ${ }^{19}$.

19 Aunque la Ley de la Ciencia, en su artículo 18.2, permite con carácter general la generación de crédito para recompensar la productividad de los investigadores funcionarios, sin embar- 
TABLA 4

Tipología de las estrategias de respuesta adaptativa de los CPI a los cambios del entorno

ALTA AUTONOMÍA DE

LOS INVESTIGADORES
Adaptación activa individual

CSIC (48\%)

INIA (21\%)

IEO $(20 \%)$

\begin{tabular}{lll}
\hline AUTONOMÍA DE LOS & Adaptación pasiva o conformista & $\begin{array}{l}\text { Adaptación activa colectiva } \\
\text { o directiva }\end{array}$ \\
INVESTIGADORES & $\begin{array}{l}\text { ISCIII (7\%) } \\
\text { CEDEX }(6 \%)\end{array}$ & CIEMAT $(31 \%)$ \\
& IGME $(8 \%)$ & INTA $(23 \%)$
\end{tabular}

BAJA AUTONOMÍA POLÍTICA

AUTONOMÍA POLÍTICA ALTA

En relación con los incentivos de carrera, el CSIC es el único en el que ésta es similar a la de las universidades, que en términos de las variables independientes se encontrarían en el mismo cuadro que el CSIC; en este centro la movilidad ascendente es posible de dos formas distintas: ascenso administrativo temporal en las posiciones jerárquicas o mediante la adquisición de un estatus de investigador superior. Otro incentivo no material que ha hecho atractivo competir por financiación externa a los investigadores del CSIC es su autonomía decisional. Los investigadores que tienen fondos externos para sus proyectos de investigación y actividades son libres de decidir en qué trabajan. Al mismo tiempo, tener fondos externos crea un ciclo de reputación para el investigador que funciona como incentivo no-material adicional para competir por los recursos.

Así pues, el CSIC representa un caso de respuesta adaptativa activa, posibilitada por la autonomía política y resultado fundamentalmente de la agregación de conductas individuales de los investigadores que responden a incenti$\operatorname{vos}^{20}$ y que no dependen demasiado de los recursos comunes organizativos para desarrollar su actividad.

go, el CSIC es el único de los OPIS que ha desarrollado esta norma y permite a cada investigador individual percibir un porcentaje (hasta un 30 por 100) de la financiación recibida externamente, de los contratos de empresas y de los proyectos de investigación financiados bajo el Programa Marco de I+D de la Unión Europea. Es también el único que, como la universidad, tiene complementos extraordinarios de productividad, que se incorporan en los salarios de los investigadores que han superado de forma exitosa una evaluación de sus actividades de investigación, que se ofrece por cada seis años de resultados y que se acumula en el tiempo (sexenios).

${ }^{20}$ Un problema distinto es la coordinación de las estrategias individuales, la acción colectiva. La reducción de la dependencia de los recursos por parte de los investigadores aumenta sus niveles de autonomía y, por tanto, las dificultades para «someterlos» a una estrategia de la dirección, lo cual puede crear problemas de coherencia organizativa. 
Por otra parte, INIA e IEO muestran un tipo de estrategia similar, aunque con resultados menores en términos de nuestra variable dependiente (en torno al 20 por 100). El que la conducta pueda ser individual lo posibilita que estos investigadores en general no dependen demasiado de los recursos comunes, pero, en ausencia de sistemas de incentivos salariales individualizados, el nivel de la respuesta es menor que en el CSIC. En el INIA sí que se estableció —-dentro de los límites de la función pública tradicional - un sistema de asignación de recompensas económicas (la productividad) basado en la determinación de los resultados investigadores. Por otro lado, INIA e IEO son centros que, además de productores de conocimiento, eran proveedores de servicios a su Ministerio de dependencia histórica. Además, el IEO, desde el punto de vista de las transferencias directas de los Presupuestos Generales del Estado, ha sido uno de los centros que ha mejorado relativamente su posición en los noventa, por lo que se podría suponer que las presiones para adaptarse han sido menores.

Ilustra un segundo tipo de estrategia un grupo de centros que recibe un montante significativo de financiación exterior: CIEMAT (31 por 100) e INTA (23 por 100). Estos centros responden a un tipo de estrategia adaptativa activa, pero de tipo colectivo. También pueden ser considerados productores de conocimiento. Su misión explícita no es tanto proveer de servicios como llevar a cabo I+D en sus áreas respectivas: energía y aeronáutica y espacio. Sus actividades se concentran en la investigación básica y desarrollo tecnológico.

Las áreas de investigación en las que se encuentran implicados requieren un alto nivel de inversión y financiación, lo que dificulta que los investigadores individuales puedan liderar la respuesta adaptativa, ya que para investigar dependen de recursos organizativos comunes que "controlan" los directores. De ahí que la dirección de los OPIS esté interesada en obtener fondos externos para las actividades de investigación. Sin embargo, aunque el nivel de financiación externa es alto, ninguno ha podido aplicar los esquemas retributivos individualizados, basados en "sexenios» o en "productividad vía artículo 18 de la Ley de la Ciencia», presentes en el CSIC; además, las perspectivas de carrera para los investigadores dependen exclusivamente de su movilidad ascendente a un puesto de trabajo mejor en términos de complementos. El CIEMAT e INTA ilustran un tipo de adaptación activa de carácter colectivo, no basada en los incentivos individuales, y posibilitada por cierto margen de maniobra con respecto a sus Ministerios, que ejercen sobre ellos una presión política modera$\mathrm{da}$, lo que hace que puedan "vender» sus resultados de investigación en mercados más amplios. La naturaleza de sus áreas de investigación puede también ayudar a explicar el nivel de financiación exterior. Los dos centros están implicados en áreas altamente internacionalizadas y ocupan posiciones de monopolio en la provisión de ese conocimiento en España, y necesitan inversiones en infraestructuras técnicamente avanzadas. Tienen fuertes incentivos para obtener fondos externos, comprometiéndose en programas de $\mathrm{I}+\mathrm{D}$ europeos $\mathrm{o}$ internacionales o con acuerdos con empresas que puedan pagar esas inversiones. 
En el tercer bloque se encuentran los centros que han seguido una estrategia más pasiva de respuesta a los problemas del entorno. El CEDEX y el IGME presentan niveles más bajos de financiación externa. Son esencialmente proveedores de servicios a sus Ministerios, y en el CEDEX la investigación es sólo una parte pequeña del trabajo. Así pues, a pesar de nuevas oportunidades para obtener financiación para la investigación, la dirección de esas organizaciones no tiene incentivos claros para hacerlo. Ninguna de ellas tiene un mercado externo alternativo para vender sus servicios. Además, en ellas no existen sistemas de compensación o carreras más allá de los esquemas retributivos tradicionales de los funcionarios. Representan casos de adaptación pasiva a los cambios en el entorno económico, que viene dada por la ausencia en la práctica de los dos tipos de autonomía que hemos analizado.

El ISCIII es un caso especial que sirve de control a nuestro argumento. En el ISCIII el estrés financiero fue limitado y, además, ni la organización ni sus investigadores modificaron su conducta. Por otro lado, el arreglo institucional y legal que sustenta el Instituto de Salud Carlos III y el Fondo de Investigaciones Sanitarias (FIS) está apoyado en la Ley General de Sanidad (14/1986) y no en la Ley de la Ciencia. Además, el ISCIII tardó años en incorporarse a la categoría de OPI. En el área de sanidad, en los recursos de investigación, hay mucho slack en las organizaciones, por lo que la presión para la obtención de los recursos para investigar quizá sea menor: la presión del entorno en este caso es pequeña, además de que el centro maneja un fondo de financiación de la investigación médica (el FIS) y es un proveedor de servicios sobre salud a su Ministerio.

En la tabla 4 se han resumido las estrategias adaptativas y el estado de la variable dependiente en los casos seleccionados, así como su relación con las dos formas de autonomía. La combinación de estas dos dimensiones de la autonomía nos ofrece elementos predictivos sobre el estado de la variable dependiente, que evolucionaría con forma de gradiente, pero que no responde a una función lineal. Así pues, el estado de la variable dependiente debe interpretarse de forma más compleja, dado que el nivel de financiación de los diversos OPIS constituye una curva que, explicada en términos de nuestras dos variables, adopta una forma de función de potencia. En el momento actual los centros de investigación podrían tener unos niveles de financiación extrapresupuestaria alta, incluso careciendo de "autonomía respecto al Ministerio», pero siempre que desarrollen trabajos y presten servicios — retribuidos por medio de convenios de financiación finalista - a su organismo de tutela. Desde este punto de partida, puede ocurrir que los niveles de financiación externa decaigan a medida que aumenta la autonomía política del centro respecto de su Ministerio, cuando se pierden las garantías de financiación, hasta el momento en que encuentran «mercados» o financiadores alternativos que puedan proveer de los fondos. Un centro en evolución puede tardar tiempo en desarrollar las «nuevas prácticas» para la captación de recursos externos, esto es, consolidar un centro basado en investigadores que compitan por los fondos para la inves- 
tigación. La transición puede ser más rápida si se produce la circunstancia de que existan mercados externos que demanden investigación y conocimiento en esas áreas.

\section{CONSIDERACIONES FINALES}

El objetivo de este trabajo ha sido explicar el proceso de adaptación organizativa de los centros públicos de investigación a los cambios en su entorno, utilizando para ello un marco analítico que combina la teoría de la dependencia de los recursos con algunos elementos del enfoque institucionalista. Los actores en los centros públicos de investigación, directivos e investigadores, se han adaptado a un entorno económico de descenso relativo de la financiación directa en los noventa, y a los cambios de un entorno político y legal que posibilitaban la búsqueda de financiación externa y que presionaba para que las agendas de investigación se alineasen con las necesidades económicas y sociales. Las respuestas al nuevo entorno económico variaron significativamente, tanto en el tipo de estrategia como en la intensidad de la reacción, a pesar de que los cambios normativos de la década anterior habían contribuido a configurar un "campo organizativo" en el que estaban los OPIS y que podría haberse generado un proceso de isomorfismo. Por el contrario, la adaptación por parte de directivos e investigadores en los distintos centros se llevó a cabo seleccionando una conducta determinada de entre las posibles.

Una vez constatada la diversidad de respuestas, medida a través del porcentaje de financiación externa, hemos argumentado que el factor explicativo fundamental ha sido el nivel de autonomía, que se compone, por una parte, de la independencia política de las organizaciones y, por otra, de la autonomía de los investigadores. Ambas dimensiones de la autonomía tienen bases fundamentalmente institucionales y normativas. La primera de ellas, por las relaciones históricas de intercambio entre los centros públicos de investigación y sus Ministerios en razón de su misión, por el margen de maniobra que las estructuras de autoridad implican y por las posibilidades de establecer vínculos comerciales con otros actores del sistema; la segunda, por la presencia relativa en las organizaciones de sistemas de incentivos individuales y de normas sobre el uso de los recursos organizativos comunes, que hacen a los investigadores más o menos dependientes de los mismos, en función de las áreas de investigación.

La combinación de los distintos niveles de estas dos dimensiones nos ha proporcionado una tipología de respuestas adaptativas probables, en las que hemos situado nuestros casos, constatando que la relación entre nuestras variables no es de carácter lineal.

La capacidad para desarrollar estrategias basadas en la obtención de financiación competitiva, tanto pública como privada, exige un cambio de contexto y un abandono relativo de las funciones de prestación de servicios a los Ministerios como contrapartida de los ingresos presupuestarios regulares. Desde este 
punto de vista, hay que mirar al pasado como un punto en un proceso histórico de desarrollo. Aunque también podría pensarse en la carencia de autonomía política como un tipo estable, en el cual se financian todas las actividades necesarias a través de las transferencias directas; sin embargo, ese entorno parece haber desaparecido definitivamente.

Quedan para un análisis futuro el estudio del impacto que la emergencia de nuevos actores de la investigación ha tenido sobre los centros públicos de $\mathrm{I}+\mathrm{D}$ y, desde luego, la comparación de éstos con la evolución y transformación de las universidades.

\section{REFERENCIAS}

Alonso, Sonia; Remo Fernández, José, y Sanz Menéndez, Luis (2001): «Spanish Public Research Centre' Responses to Change: Diversification of Funding Sources», en Deborah Cox, Philip Gummett y Katharine Barker (eds.), Government Laboratories. Transition and Transformation, Amsterdam: IOS Press, pp. 128-154.

ARTHUR, W. B. (1983): Competing technologies and lock-in by historical small events: the dynamics of allocation under increasing returns, Stanford: CEPR, WP 43.

Averch, Harvey A. (1985): A Strategic Analysis of Science \& Technology Policy, Baltimore-London: The John Hopkins University Press.

Banco Mundial (1999): El conocimiento al servicio del desarrollo. Informe sobre el desarrollo mundial, Madrid: Ediciones Mundi-prensa.

Bernal, J. D. (1939): The Social Function of Science, London: Routledge \& Kegan.

Braun, Dietmar (1993): "Who Governs Intermediary Agencies? Principal-Agent Relations in Research Policy-Making», Journal of Public Policy, vol. 13, 2: 135-162.

Burstein, Paul (1991): «Policy Domains: Organization, Culture, and Policy Outcomes», Annual Review of Sociology, 17: 327-350.

David, Paul A. (1985): "Clio and the Economics of QWERTY", American Economic Review, vol. 75, núm. 2: 332-337.

De Solla Price, D. (1963): Little science, big science... and beyond, New York: Columbia University Press, 1986.

DiMaggio, Paul J., y Powell, Walter W. (1983): «The Iron Cage Revisited: Institutional Isomorphism and Collective Rationality in Organization Fields", American Sociological Review, 48, abril: $147-160$.

Elzinga, Aant, y Jamison, Andrew (1995): "Changing Policy Agendas in Science and Technology», en S. Jasanoff, G. E. Markle, J. C. Petersen y T. Pinch (eds.), Handbook of Science and Technology Studies, Thousand Oaks-London: Sage, pp. 572-597.

Emerson, Richard M. (1962): "Power-Dependence Relations", American Sociological Review, vol. 27, Issue 1, febrero: 31-41.

European Commission (1997): Second European Report on S \& T Indicators 1997, Brussels: CEC, EUR 17639.

Gibbons, Michael; Limoges, Camile; Nowotny, Helga; Schwartzman, Simon; Scott, Peter, y Trow, Martin (1994): The New Production of Knowledge. The Dynamics of Science and Research in Contemporary Societies, London: Sage.

GómeZ-Mejía, Luis R., y BALKin, David B. (1992): «Determinants of Faculty pay: an agency theory perspective», Academy of Management Journal, vol. 35, núm. 5: 921-955.

Guston, David H. (1996): «Principal-Agent Theory and the Structure of Science Policy», Science and Public Policy, 23, 4: 229-240.

Hannan, Michael T., y Freeman, John H. (1984): «Structural Inertia and Organisational Change», American Sociological Review, vol. 49: 149-164. 
INE (2000): La estadística de I+D en España: 35 años de historia, Madrid: INE.

Konrad, A. M., y Pfeffer, J. (1990): «Do you get what you deserve? Factors affecting the relationships between productivity and pay», Administrative Science Quarterly, vol. 35: 258-285.

LÓpez FaCAL, Javier, y Represa, Domingo (1998): «Los Organismos Públicos de Investigación (OPIS)", Arbor, CLX, 629, mayo: 1-33.

March, James G. (1994): A Premier on Decision-Making, New York: Free Press.

MAYNTZ, Renate (1993): "Networks, Issues and Games: Multiorganizational Interactions in the Restructuring of a National Research System», en Fritz W. Scharpf (ed.), Games in Hierarchies and Networks, Frankfurt-Boulder (Co): Campus Verlag - Westview Press, pp. 189-210.

MEYER, John W., y RowAN, Brian (1977): «Institutionalized Organizations: Formal Structure as Myth and Ceremony», American Journal of Sociology, vol. 83, núm. 2: 340-363.

Muñoz, Emilio; SANTESMASES, M. Jesús, y ESPINOSA, Jesús (1999): Changing structure, organisation and nature of public research systems, Madrid: IESA.

OECD (1964): Country Report on the Organisation of Scientific Research: Spain, París: OECD.

- (1996): The Knowledge base economy, París: OECD.

Pfeffer, Jeffrey, y SALANCIK, Gerald R. (1978): The external control of organizations. A resource Dependence Perspective, New York: Harper \& Row.

PolanYI, Michael (1962): «The Republic of Science», Minerva, vol. I, núm. 1: 54-73.

Price, D. K. (1965): The Scientific Estate, London: Oxford University Press.

RIP, Arie (1990): «Implementation and Evaluation of Science \& Technology Priorities and Programs», en Susan E. Cozzens, Peter Healey, Arie Rip y John Ziman (eds.), The Research System in Transition, Dordrecht: Kluwer, pp. 263-280.

- (1994): "The Republic of Science in the 1990s", Higher Education, vol. 28, núm. 1: 3-23.

Romer, Paul M. (1990): «Endogenous Technological Change», Journal of Political Economy, vol. 98, núm. 5, octubre: s71-s102.

Ruivo, Beatriz (1994): "Phases" or "paradigm" of science policy?», Science and Public Policy, vol. 21: 157-164.

SAnZ MenÉndeZ, Luis (1995a): «Policy choices, institutional constraints and policy learning: The Spanish science and technology in the eighties", International Journal of Technology Management, vol. 10, núms. 4/5/6: 622-641.

- (1995b): «Research actors and the state: research evaluation and evaluation of science and technology policies in Spain», Research Evaluation, vol. 5, núm. 1, abril: 79-88.

- (1997): Estado, ciencia y tecnología en España (1939-1997), Madrid: Alianza.

SAnz Menéndez, Luis; Muñoz, Emilio, y GarCía, Clara E. (1993): «The vicissitudes of Spanish science and technology policy», Science and Public Policy, vol. 20, núm. 6, diciembre: 370-380.

SChimank, Uwe, y STUCKe, Andreas (1994a): "Coping with Trouble as a Complex Constellation of Political and Research Actors: Introducing a Theoretical Perspective», en Uwe Schimank y Andreas Stucke (eds.), Coping with Trouble. How Science reacts to Political Disturbances of Research Conditions, Frankfurt-New York: Campus Verlag - St. Martin's Press, pp. 7-34.

- (1994b): «A Theoretical Examination of the Cases: Why Coping Is Often Difficult and Defective», en Uwe Schimank y Andreas Stucke (eds.), Coping with Trouble. How Science reacts to Political Disturbances of Research Conditions, Frankfurt-New York: Campus Verlag St. Martin's Press, pp. 357-400.

ScotT, W. Richard (1981/1998): Organizations. Rational, Natural and Open Systems, Upper Saddle River (NJ): Prentice Hall (4a ed.).

- (1995): Institutions and Organisations, Sage: Thousand Oaks Ca.

Solingen, Etel (1993): «Between Markets and the State. Scientist in Comparative Perspective», Comparative Politics, vol. 26, núm. 1, octubre: 21-51.

Solow, Robert M. (1957): «Technical Change and the Aggregate Production Function», Review of Economics and Statistics, vol. XXXIX: 312-320. 
Thompson, J. D. (1967): Organizations in Action, New York: McGraw-Hill.

VAN DER MEULEN, Barend (1997): «Science policies as principal-agent games. Institutionalization and path dependency in the relation between government and science», Research Policy, vol. 27: 397-414.

Weber, M. (1919): «Science as a vocation», en H. H. Gerth y C. W. Mills (eds.), From Max Weber, New York: Oxford University Press, pp. 129-156.

\begin{abstract}
The research system is highly dependent upon the resources provided by the political system. The researchers and their respective institutions have expected public spending on $R \& D$ to increase but the rising cost of research and the emergence of financial problems in government have meant that direct implementation of $\mathrm{R} \& \mathrm{D}$ has lost ground in the governmental agenda. This situation has become evident in the state owned research centres or public research centres which have lost status in the global research activity whilst the mechanisms of competitive financing have increased as the method of governmental intervention.

This reduction in direct support is a problem which affects the conditions under which research is carried out, both for the researchers and for the centres. The aim of this paper is to analyse how a group of public research centres affected by this reduction in the direct transfers of State funds have reacted to this situation. After reviewing the different reactions to adapt to and combat the cuts in State subsidies, an institutionalist argument is built up based on the degree and type of autonomy which the centres and researchers enjoy.
\end{abstract}

